RESENHA

\title{
BEZERRA, Arthur Coelho. Cultura ilegal: as fronteiras morais da pirataria. Rio de Janeiro: Mauad X : Faperj, 2014. 240 p.
}

Juliano Borges *

Embora tecnologias de reprodução fossem relativamente difundidas no século $\mathrm{XX}$ assim como o próprio hábito de copiar bens culturais, a cópia só se tornou um problema complexo quando passou a acontecer em um contexto de vida digitalizada, assumindo implicações comerciais, jurídicas e sociológicas. De fato, as mudanças tecnológicas ocorridas na passagem do século XX para o século XXI proporcionaram oportunidades abrangentes no plano da produção e do consumo de bens culturais e estabeleceram um dilema: a cópia poderia significar tanto a democratização do acesso à arte e à ciência; como também pirataria, usurpação criminosa de direitos de autor. Essa ambiguidade é a expressão de um quadro político conflituoso, em que a legitimidade do direito de propriedade privada passa a ser questionada em nome de uma difusão mais ampla da cultura e do conhecimento.

O trabalho de Arthur Bezerra, fruto de sua tese de doutorado em sociologia pela Universidade Federal do Rio de Janeiro, aprofunda a pesquisa a respeito dos impactos das tecnologias da informação na produção cultural na contemporaneidade. Ele considera, em particular, as transformações nos planos da difusão e da produção artísticas, motivadas em grande medida pelos processos de digitalização na/da arte, avaliando como elas permitiram mudanças culturais que afetarão o valor (econômico, mas também simbólico) da criação e da fruição artísticas, em um contexto em que a informação adquire centralidade estratégica para o desenvolvimento humano.

Estruturado em duas partes, "Cultura ilegal: as fronteiras morais da pirataria" se dedica a expor, na primeira seção, o processo de conversão da cultura em mercadoria, apoiado nas críticas da Escola de Frankfurt sobre a serialização da obra de arte. No século XXI, que Bezerra chama de "época das técnicas de reprodução digital", a cultura mercadoria passa a ter também uma base digital. Convertida em informação binária, a produção intelectual pode ser armazenada, reproduzida e distribuída por meio de redes telemáticas horizontais, que independem dos processos convencionais verticais, baseados em velhas estruturas de circulação, de caráter fechado e privado.

Essa realidade estabeleceu uma notável descentralização da oferta de bens culturais, em consonância com o valor de acesso universal à cultura como direito fundamental do ser humano. Proporcionou também uma democratização dos meios de produção e o crescimento exponencial da criação amadora, com significativo impacto sobre a autonomia da representação e o fortalecimento da diversidade cultural, dinamização da produção e um alargamento do polo emissor da comunicação social. Quem consome também pode produzir e comunicar. Novos atores políticos entraram em

\footnotetext{
* Doutor em ciência política pelo Instituto Universitário de Pesquisas do Rio de Janeiro (luperj). Professor adjunto da Faculdade de Comunicação Social do IBMEC-RJ. Endereço: Rua Armando Lombardi, 940, Barra da Tijuca, CEP 22460-040, Rio de Janeiro, RJ. Telefone: (21) 22653113. E-mail: julianoborges@gmail.com.
} 
cena, animando um conjunto de teóricos otimistas com as possibilidades emancipatórias da emergente cibercultura. Porém, essas mudanças colidem frontalmente com o paradigma de (re)produção e distribuição anterior, marcado por centralização e controle oligopólico, garantido por um arcabouço jurídico internacional constituído ainda no século XIX. O dilema em torno da propriedade de bens culturais estabelece assim um conflito político que dará início a uma cruzada moral, perpetrada pelas indústrias culturais em defesa de seus interesses econômicos, diante da rápida transformação do cenário em que atuam. É nesse ponto que assume importância o termo "pirataria", cavalo de uma batalha jurídica e moral contra o uso indiscriminado das tecnologias de informação como fonte de acesso à cultura.

É na segunda parte da obra que Bezerra concentra sua crítica e analisa o conflito de interesses que emerge com a cultura digital, expondo as estratégias reativas dos grupos proprietários contra o uso da tecnologia para aquisição gratuita de bens culturais. Apoiado em uma pesquisa empírica, o trabalho identifica as representações sociais de jovens consumidores de bens culturais sobre o tema da pirataria. Observou-se, por exemplo, que a prática do acesso ilegal aos bens em questão é motivada por uma clara racionalidade econômica, explicitando, no entanto, uma variedade conflitante de entendimentos sobre o termo "pirata", que mereceu por isso um esforço particular de definição pelo autor.

Os entrevistados apontaram que entre os principais prejudicados pela pirataria estavam gravadoras e artistas. Contraditoriamente, os artistas também apareceram entre os maiores beneficiados, pois passariam a ter seu trabalho conhecido, sem depender dos esquemas comerciais e artísticos das gravadoras. Neste quesito, entretanto, chama a atenção a ausência das gigantes do mercado digital, cujo faturamento decorre da audiência obtida, em grande medida, com a reprodução não autorizada de obras audiovisuais. Sintomático que, ao não serem visadas diretamente pela cruzada moral, empresas como Google, Facebook e Yahoo tenham escapado por completo da percepção pública, embora estejam entre as principais violadoras do direito autoral.

A pesquisa mostra que há um descompasso entre o que pensam os usuários de tecnologias e o que ainda estabelece a lei, indicando que as práticas sociais vigentes são validadas por uma cultura de compartilhamento cada vez mais forte na sociedade. Para entender o lado da oferta, Bezerra realizou também um elucidativo trabalho de campo junto a vendedores de mídias piratas nas ruas do centro do Rio de Janeiro, apresentando um detalhado estudo sobre a estrutura de funcionamento do comércio ilegal, em que alguns mitos, como a relação com o "crime organizado", são questionados. A etnografia também trata do entendimento sobre o sentido de pirataria e das motivações econômicas desses trabalhadores, em constante trânsito entre as fronteiras da informalidade, da ilicitude e da ilegalidade.

Estudadas demanda e oferta, Bezerra volta-se para conhecer os argumentos e as ações dos proprietários de direitos autorais diante do conflito de interesses estabelecido. É o capítulo 4, "Os empreendedores morais da cultura", que traz as contribuições mais importantes para a compreensão de um problema político que as transformações tecnológicas e culturais colocaram. Valendo-se do conceito de empreendedorismo moral de Howard Becker, que também faz a apresentação do livro, Bezerra identifica quem são esses agentes e como se organizam politicamente, detalhando suas estratégias de ação, moralmente orientadas para reprogramar atitudes e comportamentos individuais. 
Os proprietários se constituem essencialmente de grandes corporações multinacionais, organizadas em torno de associações da indústria cinematográfica, fonográfica e, em menor medida, editorial. Em nome dos artistas, eles são os principais beneficiados econômicos pelo direito autoral. Isso se deve à existência de direitos patrimoniais associados, que asseguram proteção também àqueles que comercializam e divulgam bens culturais. Como concentram enorme poder nos mercados culturais, grandes estúdios de cinema, gravadoras e editoras conseguem impor aos artistas condições bastante desiguais nos contratos assinados, retendo assim a maior parcela dos lucros gerados pela exploração comercial de filmes, música, livros e outros conteúdos. Ao lado do distorcido sistema de arrecadação de direitos de exibição, isso explica o porquê dos autores não serem os principais interessados na defesa da lei de direitos autorais, ao contrário do que se poderia esperar.

Com seus negócios afetados e com o intuito de defender sua posição hegemônica ameaçada por um mercado em franca transformação, os "donos da cultura" passam a se organizar politicamente, orientando-se por um conjunto de estratégias calcado em dois argumentos principais, articulados em ações práticas de enfrentamento. $O$ principal motivo alegado para combater cópias não autorizadas de bens culturais não é novo, remete ao princípio fundamental do direito de autor, consagrado em 1886, pela Convenção de Berna. Ele repousa sobre a necessidade de estimular e premiar a criatividade artística, supondo que, para isso, a proteção à propriedade intelectual seja condição para que o artista possa explorar comercialmente suas próprias criações.

O segundo argumento é essencialmente econômico e afirma que a comercialização de cópias ilegais de bens culturais afetaria de maneira catastrófica a economia de um país como um todo, ao subtrair receitas com impostos e reduzir empregos formais. Esse argumento, por sua vez, articula-se com a tentativa de utilizar o termo "pirataria" como categoria de acusação. Como nos mostra Bezerra, há um uso indistinto pelos empreendedores morais da cultura de diferentes termos. Nesse contexto, pirataria, contrafação, falsificação, contrabando e tráfico de armas e drogas aparecem frequentemente como sinônimos de um mesmo crime, parte da estratégia de confundir a opinião pública, por um lado, e de agigantar o problema econômico, por outro, com o intuito de unificar politicamente setores diferentes da economia, afetados no entanto de forma particular e não relacionada com a cópia de bens culturais.

De forma objetiva, Arthur Bezerra vai apresentando e desconstruindo, um a um, os argumentos do empreendedorismo moral, expondo suas táticas, eventualmente fundadas em desinformação e má fé, no esforço de fazer valer suas garantias legais. Esse desespero pode ser lido como um reconhecimento tácito da decadência de um modelo de negócio (e do arcabouço jurídico que o protege), embutido em uma cruzada global pelo cumprimento da lei. Estaríamos experimentando um momento em que práticas sociais e suas representações alteram-se de tal forma que passam a desafiar os princípios sob os quais a lei se apoia. São transformações de fundo cultural que entram em choque com os modelos mentais anteriores, numa disputa pela imposição de novos valores, que desafiam os códigos morais e legais preestabelecidos e minam sua legitimidade.

Há uma série de evidências que expõem a fragilidade do atual marco legal de direitos autorais, tanto na eficácia da promoção de desenvolvimento econômico e social como na própria capacidade de proporcionar diversidade na produção cultural. Sua lógica privada representa um descompasso com a idéia de sociedade do 
conhecimento, aspiração própria deste milênio, e com o valor atribuído ao livre fluxo de informações como pré-requisito capaz de abastecer processos criativos inspirados no conceito de inteligência coletiva.

A ineficácia do empreendedorismo moral coloca seus promotores em uma posição desconfortável, obrigando-os a uma revisão de sua estratégia política, com a reformulação de seus argumentos e uma mudança nos modelos de negócio. Outros sistemas de licenciamento autoral, como o Creative Commons, mais abertos e sintonizados com as transformações culturais e mercadológicas, estão disponíveis e vêm ganhando espaço. Barreiras artificiais que limitam o acesso à educação, à informação e à cultura tornam-se incompatíveis com essa nova etapa histórica. Anacrônico, o empreendedorismo moral coloca-se como reação política no campo de disputa simbólica contra experiências sociais emergentes, cujos praticantes, de forma mais ou menos consciente, acabam por afirmar sua razão contra os velhos modelos de controle da informação. A lei resta em desacordo com o seu tempo, criminalizando sobretudo as novas gerações, que se desenvolvem desafiando e assumindo a inadequação jurídica como exagerada, injusta ou tão somente irrelevante. 